\title{
Development and validation of new poisoning mortality score system for patients with acute poisoning at the emergency department
}

\author{
Kap Su Han ${ }^{1 \dagger}$, Su Jin Kim ${ }^{1 \dagger}$, Eui Jung Lee ${ }^{1}$, Joong Ho Shin ${ }^{1}$, Ji Sung Lee ${ }^{2}$ and Sung Woo Lee ${ }^{1^{*}}$ (D)
}

\begin{abstract}
Background: A prediction model of mortality for patients with acute poisoning has to consider both poisoningrelated characteristics and patients' physiological conditions; moreover, it must be applicable to patients of all ages. This study aimed to develop a scoring system for predicting in-hospital mortality of patients with acute poisoning at the emergency department (ED).

Methods: This was a retrospective analysis of the Injury Surveillance Cohort generated by the Korea Center for Disease Control and Prevention (KCDC) during 2011-2018. We developed the new-Poisoning Mortality Scoring system (new-PMS) to generate a prediction model using the derivation group (2011-2017 KCDC cohort). Points were computed for categories of each variable. The sum of these points was the new-PMS. The validation group (2018 KCDC cohort) was subjected to external temporal validation. The performance of new-PMS in predicting mortality was evaluated using area under the receiver operating characteristic curve (AUROC) for both the groups.
\end{abstract}

Results: Of 57,326 poisoning cases, 42,568 were selected. Of these, 34,352 (80.7\%) and 8216 (19.3\%) were enrolled in the derivation and validation groups, respectively. The new-PMS was the sum of the points for each category of 10 predictors. The possible range of the new-PMS was 0-137 points. Hosmer-Lemeshow goodness-of-fit test showed adequate calibration for the new-PMS with $p$ values of 0.093 and 0.768 in the derivation and validation groups, respectively. AUROCs of the new-PMS were 0.941 (95\% Cl 0.934-0.949, $p<0.001$ ) and 0.946 (95\% Cl 0.929-0.964, $p<0.001)$ in the derivation and validation groups, respectively. The sensitivity, specificity, and accuracy of the newPMS (cutoff value: 49 points) were $86.4 \%, 87.2 \%$, and $87.2 \%$ and $85.9 \%, 89.5 \%$, and $89.4 \%$ in the derivation and validation groups, respectively.

Conclusions: We developed a new-PMS system based on demographic, poisoning-related variables, and vital signs observed among patients at the ED. The new-PMS showed good performance for predicting in-hospital mortality in both the derivation and validation groups. The probability of death increased according to the increase in the

\footnotetext{
*Correspondence: kuedlee@korea.ac.kr

${ }^{\dagger}$ Kap Su Han, Su Jin Kim and Sung Woo Lee contributed equally to this

article

${ }^{1}$ Department of Emergency Medicine, College of Medicine, Korea

University, Goryeodae-ro 73, Seongbuk-gu, Seoul 02841, Republic of Korea

Full list of author information is available at the end of the article
} permits use, sharing, adaptation, distribution and reproduction in any medium or format, as long as you give appropriate credit to the original author(s) and the source, provide a link to the Creative Commons licence, and indicate if changes were made. The images or other third party material in this article are included in the article's Creative Commons licence, unless indicated otherwise in a credit line to the material. If material is not included in the article's Creative Commons licence and your intended use is not permitted by statutory regulation or exceeds the permitted use, you will need to obtain permission directly from the copyright holder. To view a copy of this licence, visit http://creativecommons.org/licenses/by/4.0/. The Creative Commons Public Domain Dedication waiver (http://creativeco mmons.org/publicdomain/zero/1.0/) applies to the data made available in this article, unless otherwise stated in a credit line to the data. 
new-PMS. The new-PMS accurately predicted the probability of death for patients with acute poisoning. This could contribute to clinical decision making for patients with acute poisoning at the ED.

Keywords: Mortality, Prediction, Poisoning, Scoring system, Validation

\section{Background}

Acute poisoning is a global health problem, and prevention of mortality is essential in both intentional and accidental poisonings. Prediction of prognosis in patients with acute poisoning has clinical significance, i.e., it helps in timely and appropriate treatment. However, toxicology research lacks a well-accepted method for assessing the severity of poisoning [1-3]. The Poisoning Severity Score (PSS), which has been used in toxicology as a disease-specific scoring system, is used infrequently [4]. Further, it has been misused or modified from its original form [4]. Currently, it has limited clinical utility and is not likely to be applied to many cases owing to their unique clinical circumstances [4].

Mortality prediction in acute poisoning cases has been explored by applying various clinical scoring systems used in critical care $[5,6]$. The Acute Physiology and Chronic Health Evaluation (APACHE) score and Simplified Acute Physiology Score (SAPS) are commonly applied tools in the intensive care unit; they are used for predicting the outcomes in specific poisoning cases $[7,8]$. The mortality of patients depends on their physiological conditions and unique characteristics of the poisoning. The type of substance, route of exposure, and intent of poisoning affect the outcomes in patients with acute poisoning. Additionally, the toxic substances and their lethality are often unknown. A prediction model of mortality for patients with acute poisoning has to consider both poisoning-related characteristics and patients' physiological conditions; moreover, it must be applicable to patients of all ages. The objective of this study was to develop a scoring system for predicting mortality in patients with acute poisoning at the emergency department (ED). This work will assist in treatment allocation and therapeutic decision making at early stages for patients with acute poisoning.

\section{Methods}

\section{Study design and selection of study patients}

This study was a retrospective analysis of a prospective cohort (from 23 EDs), namely the Injury Surveillance Cohort, which was generated by the Korea Center for Disease Control and Prevention (KCDC) from 2011 to 2018. This registry comprised of prospectively collected data on epidemiology and outcome variables of patients with injuries presented at the ED [9]. The registry included cases of poisoning as those with a type of injury.
We selected patients with poisoning from this cohort. This selected registry included the baseline characteristics of patients with poisoning: age; sex; time-related factors, such as ED admission time and poison exposure time; poisoning-related variables, such as the intent of poisoning, route of exposure, type of substance (seven categories and 44 types of substances); and initial vital signs at the ED, such as systolic blood pressure (SBP), heart rate $(\mathrm{HR})$, respiration rate (RR), body temperature (BT); and AVPU (A-alert, V-verbal response, P-pain response, $U$-unresponse) scale of mental status. The registry also contained outcome-related variables, such as mortality at ED or after hospitalization.

Patients who were transferred from the initial ED to another hospital and those who had incomplete data on poisoning-related variables, initial physiological condition-related variables or outcome-related variables, and death on arrival (DOA) at the ED were excluded from this study (Fig. 1).

The selected study population was divided into two groups: the derivation group for predicting in-hospital mortality and the validation group for external validation of the prediction model developed (Fig. 1).

The Institutional Review Board of the Korea University Hospital approved this study (IRB No. 2020AN0195).

\section{Data analysis}

The primary outcome was in-hospital mortality. We compared the characteristics of poisoning patients between the derivation and validation groups (Table 1). Age, sex, time interval from poison exposure to ED admission, classes of substances, intent of poisoning, route of exposure, vital signs of the patients at the ED, and in-hospital mortality were analyzed (Table 1). For analysis, variables related to poisoning characteristics were categorized as follows: intent of poisoning: (1) unintentional, (2) intentional, and (3) unknown and route of exposure: (1) dermal, ocular, or contact; (2) oral; and (3) inhalation. There were 44 kinds of toxic substances that were classified into eight categories from A to $\mathrm{H}$. For categorization, we considered classification of the types of substances. Further, we categorized the substances under the same classification according to the mortality index (MI) of each substance: (A) pharmaceutical agents with MI of less than $0.5 \%$, (B) pharmaceutics with MI of $0.5-5 \%,(C)$ artificial toxic substances with MI less than $1.0 \%$, (D) artificial toxic substances or pesticides with MI 
KCDC-Cohort of emergency department (ED) based injury surveillance

: Jan $2011-\operatorname{Dec} 2018(\mathrm{n}=2116039)$

$\downarrow$

Injuries resulted from poisoning $(\mathrm{n}=57326)$

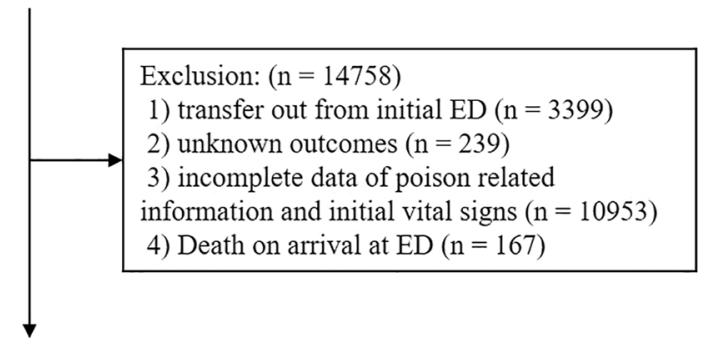

Study population $(\mathrm{N}=42,568)$

(In-hospital mortality, $\mathrm{n}=1,044$ )

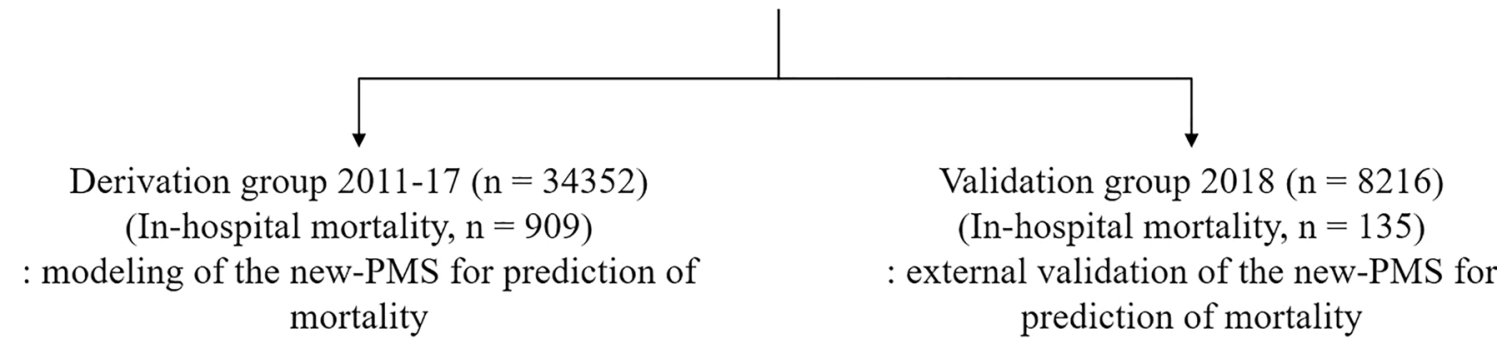

Fig. 1 Selection of study patients. PMS poisoning mortality score

of $1.0-10.0 \%,(E)$ artificial toxic substances or pesticides with MI of $11.0-20.0 \%$, (F) paraquat with MI of $52.5 \%$, (G) gases with MI less than $1.0 \%$, and $(\mathrm{H})$ natural toxic substances with MI less than $1.0 \%$ (Table 2) (Additional file 1 shows this in more detail [see Additional file 1]). MI is estimated by dividing the number of deaths by the total number of patients exposed to the specific substance. Next, it is multiplied by 100 and expressed as percentage. A patient's physiological variables included age, SBP, HR, RR, BT, and mental status (AVPU scale). They were categorized in accordance with the predictors in SAPS-II [10]. However, SAPS-II does not include RR score. Thus, we categorized RR according to the normal range (12-24 breaths/min).

\section{Development of the new poisoning mortality scoring system}

We developed a new-Poisoning Mortality Scoring system (new-PMS) to generate a prediction model for the derivation group (2011-2017 data of the KCDC cohort) (Fig. 1). In the derivation group, we compared demographics, poisoning-related variables, and initial vital signs between the patients at ED who survived and were discharged (survivor subgroup) and those who died at the hospital (in-hospital death subgroup) (Table 3). We selected variables that had statistical and clinical significance in acute poisoning as predictors for developing the new-PMS [11]. Points for categories of each predictor were computed using multivariable logistic regression. The regression coefficient for each category was converted into points by dividing the smallest regression coefficient in the model (Table 4) [12]. Sum of the points for categories in the predictors was the new-PMS.

\section{Evaluation of the new-PMS model performance}

Statistical performance of the new-PMS was assessed in terms of calibration and discrimination. Hosmer-Lemeshow goodness-of-fit test was used to evaluate the agreement between observed and predicted mortalities with respect to calibration ability of the new-PMS. The discrimination performance of the new-PMS was evaluated using sensitivity, specificity, accuracy, and area under the receiver operating characteristic curve (AUROC). The optimal cutoff value for calculating sensitivity, specificity, and accuracy was the shortest distance between each point on the ROC curve and the upper left corner. External temporal validation was achieved by calculating AUROC in the validation group (2018 data of the KCDC cohort).

For simple interpretation in a clinical setting, we created risk groups. First, we created 10 score groups of equal sizes from the Hosmer-Lemeshow test. Next, we 
Table 1 Comparison of patient characteristics between the derivation and validation groups

\begin{tabular}{|c|c|c|c|}
\hline & $\begin{array}{l}\text { Derivation group } \\
(n=34,352)\end{array}$ & $\begin{array}{l}\text { Validation group } \\
(\mathrm{n}=8,216)\end{array}$ & $p$ value \\
\hline \multicolumn{4}{|l|}{ Demographics } \\
\hline Age (years) & & & $<0.001$ \\
\hline$<40, \mathrm{n}(\%)$ & $14,432(42.0)$ & $3573(43.5)$ & \\
\hline $40-59, \mathrm{n}(\%)$ & $11,961(34.8)$ & $2698(32.8)$ & \\
\hline $60-69, \mathrm{n}(\%)$ & $3288(9.6)$ & $842(10.2)$ & \\
\hline 70-74, n (\%) & $1592(4.6)$ & $275(3.3)$ & \\
\hline $75-79, \mathrm{n}(\%)$ & $1515(4.4)$ & $364(4.4)$ & \\
\hline$\geq 80, \mathrm{n}(\%)$ & $1564(4.6)$ & $464(5.6)$ & \\
\hline \multicolumn{4}{|l|}{ Sex } \\
\hline Male: female (\%) & 15,514 (45.2): 18,838 (54.8) & 3579 (43.6): 4637 (56.4) & 0.009 \\
\hline \multicolumn{4}{|l|}{ Poisoning-related factors } \\
\hline Time from exposure to presentation (h) & $2(1-5)$ & $2(1-5)$ & 0.931 \\
\hline Intent of poisoning & & & $<0.001$ \\
\hline Unintentional, n (\%) & $12,738(37.1)$ & $2769(33.7)$ & \\
\hline Intentional, n (\%) & $21,158(61.6)$ & $5421(66.0)$ & \\
\hline Unknown, n (\%) & $456(1.3)$ & $26(0.3)$ & \\
\hline Route of poisoning & & & $<0.001$ \\
\hline Dermal, ocular, or contact, n (\%) & $346(1.0)$ & $4(0.5)$ & \\
\hline Oral ingestion, n (\%) & $27,531(80.1)$ & $6443(78.4)$ & \\
\hline Inhalation, n (\%) & $6475(18.8)$ & $1769(21.1)$ & \\
\hline Classification of substances & & & $<0.001$ \\
\hline Pharmaceutics, n (\%) & $16,449(47.9)$ & $4484(54.6)$ & \\
\hline Pesticides, (\%) & $5461(15.9)$ & $893(14.1)$ & \\
\hline Gases, n (\%) & $6160(17.9)$ & $1666(20.3)$ & \\
\hline Artificial toxic substances, n (\%) & $4876(14.2)$ & $879(10.7)$ & \\
\hline Natural toxic substances, n (\%) & $1406(4.1)$ & $294(3.6)$ & \\
\hline \multicolumn{4}{|l|}{ Initial vital signs at emergency department } \\
\hline Systolic blood pressure $(\mathrm{mmHg})$ & & & 0.081 \\
\hline$\geq 100, \mathrm{n}(\%)$ & $30,518(88.8)$ & 7349 (89.4) & \\
\hline 70-99, n (\%) & $3577(10.4)$ & $815(9.9)$ & \\
\hline$\leq 69, \mathrm{n}(\%)$ & $257(0.7)$ & $52(0.6)$ & \\
\hline Heart rate (beat/min.) & & & $<0.001$ \\
\hline 70-119, n (\%) & $27,185(79.1)$ & $6383(77.7)$ & \\
\hline $30-69, \mathrm{n}(\%)$ & $4032(11.7)$ & $1086(13.2)$ & \\
\hline $120-159, \mathrm{n}(\%)$ & $2974(8.7)$ & $724(8.8)$ & \\
\hline$\geq 160, \mathrm{n}(\%)$ & $161(0.5)$ & $23(0.3)$ & \\
\hline Respiration rate (breath/min.) & & & $<0.001$ \\
\hline $12-24, \mathrm{n}(\%)$ & $31,940(93.0)$ & $7825(95.2)$ & \\
\hline$\leq 11$ or $\geq 25, \mathrm{n}(\%)$ & $2412(7.0)$ & $391(4.8)$ & \\
\hline Body temperature $\left({ }^{\circ} \mathrm{C}\right)$ & & & 0.885 \\
\hline$<39, \mathrm{n}(\%)$ & $34,276(99.8)$ & 8199 (99.8) & \\
\hline$\geq 39, \mathrm{n}(\%)$ & $76(0.2)$ & $17(0.2)$ & \\
\hline Mental status, n (\%) & & & $<0.001$ \\
\hline Alert & $24,448(71.2)$ & $5517(67.1)$ & \\
\hline Verbal response & $5668(16.5)$ & $1628(19.8)$ & \\
\hline Pain response & $3646(10.6)$ & $931(11.3)$ & \\
\hline Unresponse & $590(1.7)$ & $140(1.7)$ & \\
\hline \multicolumn{4}{|l|}{ Outcome } \\
\hline In-hospital mortality, n (\%) & 909 (2.6) & $135(1.6)$ & $<0.001$ \\
\hline
\end{tabular}


Table 2 Category of exposed of substances according to the class of the substance and the mortality index in the derivation group

\begin{tabular}{llll}
\hline Category & Name of substance & & \\
\hline A & (1) Hormones, hormone antagonists, contraceptions & (2) Diagnostic reagents & (3) Vitamin, dietary supplements \\
& (4) Topical preparations & (5) Acetaminophen & (6) Antipsychotics \\
(7) Antidepressant & (8) Zolpidem & (9) Doxylamine \\
& (10) Unspecified sedatives, antipsychotics, hypnotics & (11) Benzodiazepine & (3) Cold and cough preparation \\
(1) Peptic, gastrointestinal drugs & (2) Antihistamine & (6) Cardiovascular drugs \\
(4) Unspecified therapeutic drugs & (5) Anticonvulsants & (9) Opioid \\
& (7) Unspecified analgesics & (8) Antibiotics, antifungals & (12) Oral hypoglycemic drugs \\
(10) Stimulants, street drugs & (11) Asthma therapies & (3) Hydrocarbons \\
(1) Alcohols (liquor, ethanol, methanol) & (2) Heavy metals & (3) Unspecified acid \\
(4) Chlorine bleach, sodium hypochlorite & (2) Unspecified alkali & (7) Pyrethroid \\
(1) Unspecified artificial toxic substances & (4) Unspecified corrosive agents & (6) Unspecified insecticides & (10) Glyphosate \\
(5) Rodenticide & (9) Unspecified herbicides & (3) Carbamate \\
(8) Unspecified pesticides & (1) Glacial acetic acid & & (2) Unspecified gases
\end{tabular}

categorized them into the following four risk groups according to morality of the score groups: very low for less than $0.1 \%$, low for $0.1-0.9 \%$, intermediate for $1.0-$ $9.9 \%$, and high risk for $10.0 \%$ or higher [13]. AUROC and observed mortalities were investigated in the derivation and validation groups, respectively $[11,13]$. Additionally, we introduced an equation for calculating the predicted mortality from logistic regression of the new-PMS.

\section{Statistical analyses}

Continuous variables were reported as medians with interquartile ranges. Differences in the medians were compared using the Mann-Whitney $U$ test. Categorical variables were compared using the Chi-square test. Sensitivity, specificity, accuracy, and AUROC were reported with 95\% confidence intervals (CIs). All statistical analyses were performed using SPSS version 20.0 (IBM Corp., Armonk, NY, USA). Two-tailed $p$ values less than 0.05 were considered statistically significant.

\section{Results}

\section{Selection of the study population and outcomes}

Of the 57,326 poisoning cases, 14,758 (25.7\%) were excluded (Fig. 1). Of the 42,568 included patients, 34,352 $(80.7 \%)$ and 8216 (19.3\%) were enrolled in the derivation and validation groups, respectively (Fig. 1). Among the study population, the median time from poison exposure to ED presentation was $2.0 \mathrm{~h}$ (interquartile range 1.0-2.0 h). The incidence of in-hospital mortality was 909
(2.6\%) and $135(1.6 \%)$ for the derivation and validation groups, respectively $(p<0.001)$ (Table 1$)$. Characteristics of the derivation and validation groups are presented in Table 1.

\section{Development of the new-PMS in the derivation group}

We compared characteristics between the survivor and in-hospital death subgroups within the derivation group (Table 3). The demographics, poisoning-related variables, and initial vital signs of each subgroup are shown in Table 3. Patients of the in-hospital death subgroup showed higher likelihood of being older, male, undergoing intentional poisoning, oral ingestion, and pesticide poisoning; they also initially presented low SBPs, high HRs, high RRs, and altered mental statuses compared with those in the survivor subgroup. Time from poison exposure to ED presentation was not significantly different between the survivor and in-hospital death subgroups $(p=0.057)$.

We selected 10 predictors from these variables considering clinical reasoning and statistical significance. The 10 predictors (age, sex, type of substance, intent of poisoning, route of poisoning, SBP, HR, RR, BT, and AVPU scale) and categories of each predictor are presented in Table 4. Multivariable logistic regression was used to calculate the points for categories of each predictor. First, we estimated the regression coefficient (B) for categories of each predictor in the multivariable logistic regression model. Next, base constant B was selected as the smallest 
Table 3 Comparison of characteristics between the survivor and in-hospital death subgroups in the derivation group

\begin{tabular}{|c|c|c|c|}
\hline & $\begin{array}{l}\text { Survivor } \\
(\mathrm{n}=33,443)\end{array}$ & $\begin{array}{l}\text { In-hospital death } \\
(\mathrm{n}=909)\end{array}$ & $p$ value \\
\hline \multicolumn{4}{|l|}{ Demographics } \\
\hline \multicolumn{4}{|l|}{ Age (years) } \\
\hline$<40, \mathrm{n}(\%)$ & $14,373(43.0)$ & $59(6.5)$ & $<0.001$ \\
\hline $40-59, \mathrm{n}(\%)$ & $11,732(35.1)$ & $229(25.2)$ & \\
\hline $60-69, \mathrm{n}(\%)$ & $3139(9.4)$ & $149(16.4)$ & \\
\hline $70-74, \mathrm{n}(\%)$ & $1438(4.3)$ & $154(16.9)$ & \\
\hline $75-79, \mathrm{n}(\%)$ & $1374(4.1)$ & $141(15.5)$ & \\
\hline$\geq 80, \mathrm{n}(\%)$ & $1387(4.1)$ & $177(19.5)$ & \\
\hline \multicolumn{4}{|l|}{ Sex } \\
\hline Male: female (\%) & 14,892(44.5): $18,551(55.5)$ & $622(68.4): 287(31.6)$ & $<0.001$ \\
\hline \multicolumn{4}{|l|}{ Poisoning-related factors } \\
\hline Time from exposure to presentation (h) & $2(1-5)$ & $2(1-5)$ & 0.557 \\
\hline Intent of poisoning & & & $<0.001$ \\
\hline Unintentional, n (\%) & $12,629(37.8)$ & $109(12.0)$ & \\
\hline Intentional, n (\%) & $20,403(61.0)$ & $755(83.1)$ & \\
\hline Unknown, n (\%) & $411(1.2)$ & $45(5.0)$ & \\
\hline Route of poisoning & & & $<0.001$ \\
\hline Dermal, ocular, or contact, n (\%) & $344(0.8)$ & $2(0.2)$ & \\
\hline Oral ingestion, $n(\%)$ & $26,664(79.7)$ & $867(95.4)$ & \\
\hline Inhalation, n (\%) & $6435(19.2)$ & $40(4.4)$ & \\
\hline Category of substances & & & $<0.001$ \\
\hline $\mathrm{A}, \mathrm{n}(\%)$ & $12,609(37.7)$ & $41(4.5)$ & \\
\hline $\mathrm{B}, \mathrm{n}(\%)$ & $3763(11.3)$ & $36(4.0)$ & \\
\hline C, n (\%) & $1530(4.6)$ & $12(1.3)$ & \\
\hline $\mathrm{D}, \mathrm{n}(\%)$ & $7153(21.4)$ & $372(40.9)$ & \\
\hline$E, n(\%)$ & $584(1.7)$ & $90(9.9)$ & \\
\hline $\mathrm{F}, \mathrm{n}(\%)$ & $283(0.8)$ & $313(34.4)$ & \\
\hline $\mathrm{G}, \mathrm{n}(\%)$ & $6123(18.3)$ & $37(4.1)$ & \\
\hline $\mathrm{H}, \mathrm{n}(\%)$ & $1398(4.2)$ & $8(0.9)$ & \\
\hline \multicolumn{4}{|l|}{ Initial vital signs at emergency department } \\
\hline Systolic blood pressure $(\mathrm{mmHg})$ & & & $<0.001$ \\
\hline$\geq 100, \mathrm{n}(\%)$ & $29,837(89.2)$ & $681(74.9)$ & \\
\hline $70-99, \mathrm{n}(\%)$ & $3418(10.2)$ & $159(17.5)$ & \\
\hline$\leq 69, \mathrm{n}(\%)$ & $188(0.6)$ & $69(7.6)$ & \\
\hline Heart rate (beat/min.) & & & $<0.001$ \\
\hline 70-119, n (\%) & $26,517(79.3)$ & $668(73.5)$ & \\
\hline $30-69, n(\%)$ & $3913(11.7)$ & $119(13.1)$ & \\
\hline $120-159, \mathrm{n}(\%)$ & $2867(8.6)$ & $107(11.8)$ & \\
\hline$\geq 160, \mathrm{n}(\%)$ & $146(0.4)$ & $15(1.7)$ & \\
\hline Respiration rate (breath/min.) & & & $<0.001$ \\
\hline $12-24, n(\%)$ & $31,193(93.3)$ & $747(82.2)$ & \\
\hline$\leq 11$ or $\geq 25, n(\%)$ & $2250(6.7)$ & $162(17.8)$ & \\
\hline Body temperature $\left({ }^{\circ} \mathrm{C}\right)$ & & & 0.004 \\
\hline$<39, \mathrm{n}(\%)$ & $33,374(99.8)$ & $902(99.2)$ & \\
\hline$\geq 39, \mathrm{n}(\%)$ & $69(0.2)$ & $7(0.8)$ & \\
\hline Mental status, n (\%) & & & $<0.001$ \\
\hline Alert & $24,066(72.0)$ & $382(42.0)$ & \\
\hline Verbal response & $5491(16.4)$ & $177(19.5)$ & \\
\hline Pain response & $3420(10.2)$ & $226(24.9)$ & \\
\hline Unresponse & $466(1.4)$ & $124(13.6)$ & \\
\hline
\end{tabular}


Table 4 Multivariable logistic regression for the calculation of the new-poisoning mortality scores (PMSs) for each of category of each variable in the acute poisoning patients

\begin{tabular}{|c|c|c|c|c|}
\hline & B & Points $=B / 0.124$ & Odd ratio ( $95 \%$ confidence interval) & $p$ value \\
\hline \multicolumn{5}{|l|}{ Demographics } \\
\hline \multicolumn{5}{|l|}{ Age (years) } \\
\hline$<40, \mathrm{n}(\%)$ & Reference & 0 & 1 & $<0.001$ \\
\hline $40-59, \mathrm{n}(\%)$ & 0.815 & 7 & $2.260(1.644-3.107)$ & $<0.001$ \\
\hline $60-69, \mathrm{n}(\%)$ & 1.435 & 12 & $4.198(2.973-5.929)$ & $<0.001$ \\
\hline $70-74, \mathrm{n}(\%)$ & 2.003 & 16 & $7.413(5.201-10.566)$ & $<0.001$ \\
\hline $75-79, \mathrm{n}(\%)$ & 1.955 & 16 & $7.066(4.925-10.140)$ & $<0.001$ \\
\hline$\geq 80, \mathrm{n}(\%)$ & 2.395 & 19 & $10.968(7.737-15.548)$ & $<0.001$ \\
\hline \multicolumn{5}{|l|}{ Sex } \\
\hline Female & Reference & 0 & 1 & \\
\hline Male & 0.436 & 4 & $1.547(1.301-1.838)$ & $<0.001$ \\
\hline \multicolumn{5}{|l|}{ Poisoning-related factors } \\
\hline \multicolumn{5}{|l|}{ Intent of poisoning } \\
\hline Unintention & Reference & 0 & 1 & $<0.001$ \\
\hline intention & 1.039 & 8 & $2.826(2.215-3.605)$ & $<0.001$ \\
\hline Unknown & 1.073 & 9 & $2.924(1.803-4.742)$ & $<0.001$ \\
\hline \multicolumn{5}{|l|}{ Route of poisoning } \\
\hline Dermal, ocular, or contact & Reference & 0 & 1 & 0.274 \\
\hline Oral & 1.006 & 8 & $2.734(0.652-11.456)$ & 0.169 \\
\hline Inhalation & 0.592 & 5 & $1.808(0.332-9.835)$ & 0.493 \\
\hline \multicolumn{5}{|l|}{ Category of substances } \\
\hline A, n (\%) & Reference & 0 & 1 & $<0.001$ \\
\hline $\mathrm{B}, \mathrm{n}(\%)$ & 1.373 & 11 & $3.946(2.482-6.273)$ & $<0.001$ \\
\hline C, n (\%) & 1.817 & 15 & $6.151(3.159-11.978)$ & $<0.001$ \\
\hline $\mathrm{D}, \mathrm{n}(\%)$ & 2.654 & 21 & $14.213(10.134-19.934)$ & $<0.001$ \\
\hline$E, n(\%)$ & 3.36 & 27 & $28.797(19.152-43.299)$ & $<0.001$ \\
\hline $\mathrm{F}, \mathrm{n}(\%)$ & 5.866 & 47 & $352.781(241.570-515.191)$ & $<0.001$ \\
\hline $\mathrm{G}, \mathrm{n}(\%)$ & 1.801 & 15 & $6.054(2.199-16.670)$ & $<0.001$ \\
\hline$H, n(\%)$ & 1.492 & 12 & $4.444(1.989-9.931)$ & $<0.001$ \\
\hline \multicolumn{5}{|c|}{ Vital signs at emergency department } \\
\hline \multicolumn{5}{|c|}{ Systolic blood pressure (mmHg) } \\
\hline$\geq 100$ & Reference & 0 & 1 & $<0.001$ \\
\hline $70-99$ & 0.734 & 6 & $2.084(1.654-2.627)$ & $<0.001$ \\
\hline$\leq 69$ & 1.903 & 15 & 6.704 (4.563-9.849) & $<0.001$ \\
\hline \multicolumn{5}{|l|}{ Heart rate (beats/min.) } \\
\hline $70-119$ & Reference & 0 & 1 & 0.001 \\
\hline $30-69$ & 0.124 & 1 & $1.132(0.885-1.447)$ & 0.323 \\
\hline $120-159$ & 0.458 & 4 & $1.581(1.197-2.087)$ & 0.001 \\
\hline$\geq 160$ & 0.984 & 8 & 2.675 (1.294-5.530) & 0.008 \\
\hline \multicolumn{5}{|l|}{ Respiration rate (breaths/min.) } \\
\hline $12-24$ & Reference & 0 & 1 & $<0.001$ \\
\hline$\leq 11$ or $\geq 25$ & 0.663 & 5 & $1.941(1.529-2.464)$ & $<0.001$ \\
\hline \multicolumn{5}{|l|}{ Body temperature $\left({ }^{\circ} \mathrm{C}\right)$} \\
\hline$<39$ & Reference & 0 & 1 & \\
\hline$\geq 39$ & 0.684 & 6 & $1.981(0.642-6.116)$ & 0.235 \\
\hline \multicolumn{5}{|l|}{ Mental status } \\
\hline Alert & Reference & 0 & 1 & $<0.001$ \\
\hline Verbal response & 0.61 & 5 & $1.841(1.474-2.300)$ & $<0.001$ \\
\hline Pain response & 1.017 & 8 & $2.765(2.218-3.446)$ & $<0.001$ \\
\hline Unresponse & 2.033 & 16 & 7.638 (5.618-10.386) & $<0.001$ \\
\hline
\end{tabular}


Table 4 (continued)

Base constant B was selected as the smallest regression coefficient in the model, which was 0.124

The new-PMS was the sum of the point of each variable. The possible range of new-PMS was 0 to 137 points

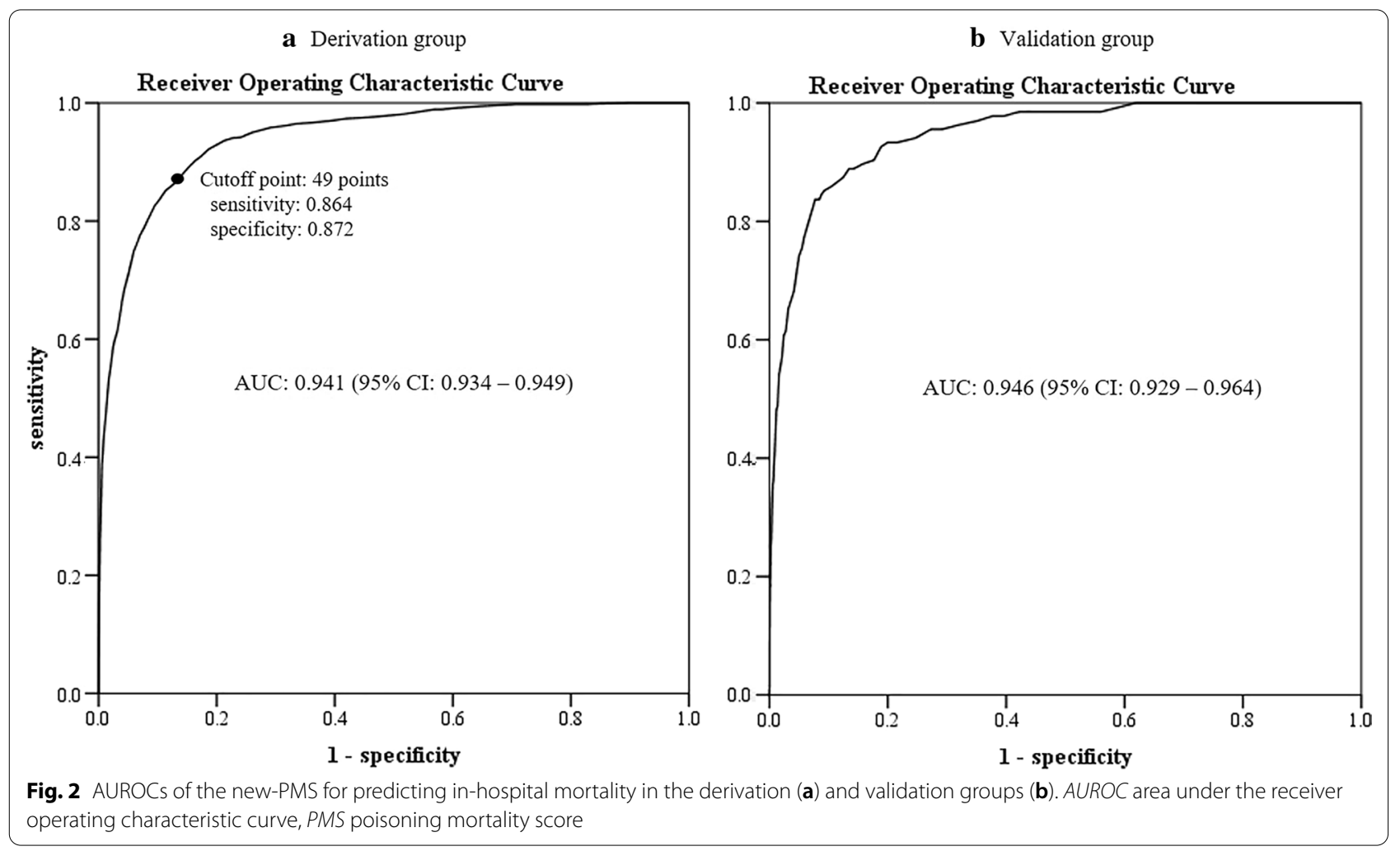

Table 5 The performance of the new-PMS for predicting mortality

\begin{tabular}{lll}
\hline Statistics & Derivation group $(\mathbf{n}=\mathbf{3 4 , 3 5 2})$ & Validation group ( $\mathbf{n = 8 2 1 6 )}$ \\
\hline Hosmer-Lemeshow goodness-of-fit test & $p=0.093$ & $p=0.768$ \\
AUROC $(95 \% \mathrm{Cl})$ & $0.941(0.934-0.949)$ & $0.946(0.929-0.964)$ \\
Optimal cutoff value & 49 points & 49 points \\
Sensitivity $(95 \% \mathrm{Cl})$ & $0.864(0.841-0.886), 785 / 909^{\mathrm{a}}$ & $0.859(0.801-0.918), 116 / 135^{\mathrm{a}}$ \\
Specificity $(95 \% \mathrm{Cl})$ & $0.872(0.868-0.876), 29,162 / 33,443^{\mathrm{a}}$ & $0.895(0.888-0.902), 7233 / 8081^{\mathrm{a}}$ \\
Accuracy $(95 \% \mathrm{Cl})$ & $0.872(0.868-0.875), 29,947 / 34,352^{\mathrm{a}}$ & $0.894(0.888-0.901), 7349 / 8216^{\mathrm{a}}$ \\
\hline
\end{tabular}

PMS poisoning mortality score, $A U R O C$ area under receiver operating characteristic curve, $\mathrm{Cl}$ confidence interval

${ }^{\text {a }}$ Number of patients

$\mathrm{B}$ in the model. The base constant $\mathrm{B}$ was 0.124 in the multivariable model (Table 4). We converted the B category of each predictor into points using the formula B/0.124 (Table 3) [11]. Points for each predictor are displayed in Table 4. The new-PMS was the sum of points of each predictor. The minimum-to-maximum possible range of the new-PSS was $0-137$ points. Real ranges of the new-PSS were $0-117$ points and $8-115$ points in the derivation and validation groups, respectively.

\section{Performance evaluation of the new-PMS}

The AUROC of 0.941 (95\% CI: 0.934-0.949) in the derivation group was significantly high $(p<0.001)$ (Fig. 2a). The optimal cutoff value was 49 points. Statistical performance of the new-PMS in predicting in-hospital 
Table 6 Risk groups within the derivation and validation groups

\begin{tabular}{llll}
\hline Risk group & New-PMS & \multicolumn{2}{l}{ Observed mortality (\%) } \\
\cline { 3 - 4 } & & $\begin{array}{l}\text { Derivation cohort } \\
(\mathbf{n}=\mathbf{3 4 , 3 5 2})\end{array}$ & $\begin{array}{l}\text { Validation cohort } \\
(\mathbf{n}=\mathbf{8 2 1 6})\end{array}$ \\
\hline Very low & $0-27$ & $5 / 11,776(0.04)$ & $0 / 3038(0.00)$ \\
Low & $28-40$ & $40 / 12,979(0.31)$ & $9 / 3266(0.28)$ \\
Intermediate & $41-55$ & $170 / 6717(2.53)$ & $24 / 1322(1.82)$ \\
High & $\geq 56$ & $694 / 2880(24.10)$ & $102 / 548(18.61)$ \\
\hline
\end{tabular}

PMS poisoning mortality score

a Sum of scores for each variable as shown in Table 4

mortality for acute poisoning cases is shown in Table 5 . External temporal validation analysis of the new-PMS also showed a significantly high AUROC of 0.946 (95\% CI $0.929-0.964)(p<0.001)$ in the validation group (Fig. $2 \mathrm{~b})$.

During risk grouping for simple interpretation in clinical settings, patients were classified according to the new-PMS into four categories: 0-27 points, very low-risk; $28-40$ points, low risk; 41-55 points, intermediate risk; and 56 points or more, high risk. Table 6 presents the observed mortality according to the four risk groups. AUROCs of risk grouping were 0.920 (95\% CI $0.912-0.928, p<0.001$ ) and 0.927 (95\% CI 0.909$0.946, p<0.001)$ in the derivation and validation groups, respectively. The equation for predicting in-hospital mortality was as follows: Predicted mortality $=1 /\left(1+\mathrm{e}^{-\mathrm{z}}\right)$, $\mathrm{z}=-9.763+0.126 \times$ new-PMS.

\section{Discussion}

Outcome prediction systems for patients with poisoning are rarely studied. Thus, we developed the new-PMS to predict the probability of mortality among patients with acute poisoning. The new-PMS is a simplified scoring system that has several benefits, namely usage of objective predictors, rapid assessment of mortality risk, and early applicability in clinical settings.

Several models for severity of illness that have been used in intensive care units (ICUs) can be applied to patients with acute poisoning. Silakhori [14] reported that the APACHE-II, APACHE-IV, SAPS-II, and Sequential Organ Failure Assessment have acceptable discriminatory power for patients with poisoning, and APACHE II can be used for mortality prediction during early days of admission. However, on the first day of admission, AUROC of APACHE-II was only 0.77 in their study. They did not consider poisoning-related factors. While predicting the outcomes of acute poisoning in clinical settings, we have to consider both the physiological condition of the patient and unique characteristics of the poisoning. The new-PMS reflected two major characteristics of acute poisoning among patients, namely the characteristics of poisoning and the early physiological condition after poisoning.

Lionte [2] developed a risk-prediction nomogram for in-hospital mortality among adults poisoned with drugs and non-pharmaceutical agents. The AUROC of their nomogram was 0.949 for the validation group, which was similar to our AUROC (0.946) for the validation group. However, Lionte's study used some test variables as predictors and included only those patients who were in the ICU or non-ICU ward, which had a small sample size. Our study was different from Lionte's study because we performed risk grouping and introduced an equation (for clinical use) for predicting in-hospital mortality instead of using a nomogram. Further, our study included all patients with acute poisoning hospitalized, discharged from the ED with a large sample size of 23 ED-based cohort. We expect that the new-PMS can be applied for very mild to serious acute poisoning cases using the risk group and calculation of predicted mortality at the ED.

Given the unique characteristics of individual xenobiotics, many researchers have attempted to apply physiological scoring systems in patients with specific xenobiotic poisoning [7, 8, 15-18]. Peter [7] compared the performance of APACHE-II, SAPS-II, and PSS in acute organophosphate poisoning. In their study, AUROC was 0.77, 0.75 , and 0.67 for APACHE-II, SAPS-II, and PSS, respectively. Previous prediction outcome models for specific toxic substances have limited value when they are applied to a wide range of patients with poisoning. In the current study, the new-PMS showed excellent performance in predicting mortality, with an AUROC of over 0.9 in all patients with acute poisoning, regardless of the cause of poisoning, type of substance, age, and sex. The present study was an attempt to develop a new scoring system (as an alternative to PSS) for outcome prediction in patients with poisoning.

We used multivariable logistic regression method to assign points for categories of each predictor. This method is commonly used for developing prognosis prediction models $[11,12]$. This approach has been used in numerous studies to create a risk scoring system $[19,20]$. The reference category of each predictor was determined considering the lowest mortality in SAPS II as the reference category or normal physiological variable value [10]. For example, the mortality of 40 -year-olds was $0.04 \%$, which was the lowest among all age-groups, and the point in SAPS II was 0 (Table 2).

Performance of the new-PMS was excellent according to the general guideline of AUROC in both the derivation and validation groups [21]. In simulation studies, the external validation of a prediction model requires a minimum of 100 events of the primary outcome because 
a small external validation study is unreliable and inaccurate [22-24]. Our validation group had 135 mortality cases from a total of 8216 poisoning cases.

For ease of use in clinical settings, we constructed four risk groups according to the new-PMS. This risk group showed a high AUROC (0.927) in the validation group. The observed mortalities increased according to the grade of risk score and showed agreement with the probability of death in the derivation and validation groups. We expect the new-PMS to be useful for objective discrimination between very-low-risk or low-risk patients, which can reduce unnecessary hospitalization. Moreover, patients with high scores can be transferred to the poisoning treatment center at early stages of treatment. Furthermore, the risk of mortality sharply increased in patients with acute poisoning with intermediate- and high-risk scores of the new-PMS. These results suggested that toxicological-specific treatment and early hemodynamic stabilization for intermediate- and high-risk patients at the ED may improve their clinical outcomes. The new PMS will contribute to clinical decision making and therapeutic guidance for patients with acute poisoning.

\section{Limitations}

First, in this study, we excluded cases that had missing values of poisoning, outcome, and vital signs-related variables. The traditional "complete cases" analysis may lead to selection bias of subjects and statistically inefficient results [11]. Additionally, we excluded patients with DOA from this study because we considered that these patients required no specific treatments for acute poisoning. Second, the amount of exposure in cases of oral ingestion and the duration of exposure in cases of inhalation or surface absorption are important for predicting the outcomes of acute poisoning among patients. Unfortunately, our cohort did not have data on the amount of exposure and envenomation, such as animal bites. However, the new-PMS developed in this study included the unique characteristics of poisoning, such as intent and route of poisoning. Third, we categorized the toxic substances into eight categories comprising 44 specific substances. This is because all the 44 substances could not be included in the multivariable logistic regression. The clinical severity of poisoning can range from asymptomatic to lethal, depending on specificities of the toxin. For example, specific toxic substances such as paraquat are known to have high mortality irrespective of other predictors [25]. In this study, we considered paraquat as a separate category of substance. Machine learning systems have the potential to predict mortality or carry out early detection of diseases among patients in the ED [26].
Thus, we can try using several machine learning techniques with the 44 special substances without categorization for better performance of prediction models in the future. Lastly, the observed mortalities in this study were as low as $2.6 \%$ and $1.6 \%$ for the derivation and validation groups, respectively. There is a risk of overestimating/ over-fitting the predictive performance of the model if the number of predictors is much larger than the number of outcome events [11].

\section{Conclusions}

We developed a new PMS system based on demographic, poisoning-related variables, and vital signs among patients at the ED. The new-PMS showed good performance for predicting in-hospital mortality in both the derivation and validation groups, which is objective and is applicable at an early stage of poisoning. The new-PMS will contribute to clinical decision making for patients with acute poisoning at the ED.

\section{Supplementary Information}

Supplementary information accompanies this paper at https://doi. org/10.1186/s13054-020-03408-1.

Additional file 1. Substance category according to class of the substance and mortality index.ù

\section{Acknowledgements \\ None.}

\section{Author's contribution}

KSH, SJK, and SWL conceived and designed the study and wrote the manuscript. KSH managed and analyzed the data, including data quality control. LJS provided advice on statistics. All authors contributed substantially to the writing of the manuscript. All authors read and approved the final manuscript.

\section{Funding}

This work was funded by Korea University (K1925141). Kap Su Han received this funding. The funding source had no role in the study design, data collection, data analysis, data interpretation, or writing of the report.

\section{Availability of data and materials}

The datasets during and/or analyzed during the current study are available from the corresponding author upon reasonable request.

\section{Ethics approval and consent to participate}

This study was approved by the Institutional Review Board of Korea University Hospital (\#IRB No. 2020AN0195). This was a retrospective study based on the de-identified administrative database; therefore, informed consent was waived.

\section{Consent for publication}

Not applicable.

\section{Competing interests}

The authors declare no competing interests. Neither the entire paper nor any part of its contents have been published or accepted by another journal. The paper has not been submitted in its entirety, or in part, to any other journal. 


\section{Author details}

${ }^{1}$ Department of Emergency Medicine, College of Medicine, Korea University, Goryeodae-ro 73, Seongbuk-gu, Seoul 02841, Republic of Korea. ${ }^{2}$ Clinical Research Center, Asan Institute for Life Sciences, Asan Medical Center, 88 Olympic-ro 43gil, Songpa-gu, Seoul 05505, Republic of Korea.

Received: 9 September 2020 Accepted: 24 November 2020 Published online: 18 January 2021

\section{References}

1. Persson HE, Sjöberg GK, Haines JA, Pronczuk de Garbino J. Poisoning severity score. Grading of acute poisoning. J Toxicol Clin Toxicol. 1998;36(3):205-13.

2. Lionte C, Sorodoc V, Jaba E, Botezat A. Development and validation of a risk-prediction nomogram for in-hospital mortality in adults poisoned with drugs and nonpharmaceutical agents: an observational study. Medicine. 2017;96(12):e6404.

3. Cheung R, Hoffman RS, Vlahov D, Manini AF. Prognostic utility of initial lactate in patients with acute drug overdose: a validation cohort. Ann Emerg Med. 2018;72(1):16-23.

4. Schwarz ES, Kopec KT, Wiegand TJ, Wax PM, Brent J. Should we be using the poisoning severity score? J Med Toxicol. 2017;13(2):135-45.

5. Alizadeh AM, Hassanian-Moghaddam H, Shadnia S, Zamani N, Mehrpour O. Simplified acute physiology score ii/acute physiology and chronic health evaluation ii and prediction of the mortality and later development of complications in poisoned patients admitted to intensive care unit. Basic Clin Pharmacol. 2014;115(3):297-300.

6. Banderas-Bravo ME, Arias-Verdu MD, Macias-Guarasa I, Aguilar-Alonso E, Castillo-Lorente E, Perez-Costillas L, et al. Patients admitted to three Spanish intensive care units for poisoning: type of poisoning, mortality, and functioning of prognostic scores commonly used. Biomed Res Int. 2017;2017:5261264.

7. Peter JV, Thomas L, Graham PL, Moran JL, Abhilash KPP, Jasmine S, et al. Performance of clinical scoring systems in acute organophosphate poisoning. Clin Toxicol. 2013;51(9):850-4

8. Bilgin TE, Camdeviren H, Yapici D, Doruk N, Altunkan AA, Altunkan Z, et al. The comparison of the efficacy of scoring systems in organophosphate poisoning. Toxicol Ind Health. 2005;21(7-8):141-6.

9. Korea Center for Disease Control and Prevention. Injury prevention for healthy and safe society. 2020. http://www.cdc.go.kr/contents. es?mid=a20602040000. Accessed 15 Aug 2020.

10. Le Gall JR, Lemeshow S, Saulnier F. A new simplified acute physiology score (SAPS II) based on a European/North American multicenter study. JAMA. 1993:270(24):2957-63.

11. Han K, Song K, Choi BW. How to develop, validate, and compare clinical prediction models involving radiological parameters: study design and statistical methods. Korean J Radiol. 2016;17(3):339-50.

12. Sullivan LM, Massaro JM, D'Agostino RB Sr. Presentation of multivariate data for clinical use: the Framingham Study risk score functions. Stat Med. 2004;23(10):1631-60.

13. Chua SL, Chow WL. Development of predictive scoring model for risk stratification of no-show at a public hospital specialist outpatient clinic. Proc Singap Healthc. 2018;28(2):96-104.
14. Silakhori S, Dadpour B, Khadem-Rezaiyan M, Sedaghat A, Mirzakhani F. Comparing APACHE II, APACHE IV, SAPS II, and SOFA predictive power in poisoned patients admitted to the intensive care unit. Int J Med Toxicol Forensic. 2020;10(2):28814.

15. Shadnia S, Darabi D, Pajoumand A, Salimi A, Abdollahi M. A simplified acute physiology score in the prediction of acute organophosphate poisoning outcome in an intensive care unit. Hum Exp Toxicol. 2007;26(8):623-7.

16. Sheta AA, El-Banna AS, Abd Elmeguid R, Mohamed HE, Gad NH. A study of the predictive factors of mortality in acute poisoning with aluminum phosphide with special reference to echocardiography and SOFA score. Environ Sci Pollut Res. 2019;26(32):33135-45.

17. Cho YS, Moon JM, Chun BJ, Lee BK. USE OF qSOFA score in predicting the outcomes of patients with glyphosate surfactant herbicide poisoning immediately upon arrival at the emergency department. Shock. 2019;51(4):447-52

18. Kim DS, Kang C, Kim DH, Kim SC, Lee SH, Jeong JH, et al. External validation of the prognostic index in acute paraquat poisoning. Hum Exp Toxicol. 2016;35(4):366-70.

19. Schnabel RB, Sullivan LM, Levy D, Pencina MJ, Massaro JM, D'Agostino RB Sr, et al. Development of a risk score for atrial fibrillation (Framingham Heart Study): a community-based cohort study. Lancet. 2009:373(9665):739-45.

20. Imperiale TF, Monahan PO, Stump TE, Glowinski EA, Ransohoff DF. Derivation and validation of a scoring system to stratify risk for advanced colorectal neoplasia in asymptomatic adults: a cross-sectional study. Ann Intern Med. 2015:163(5):339-46.

21. Muller MP, Tomlinson G, Marrie TJ, Tang P, McGeer A, Low DE, et al. Can routine laboratory tests discriminate between severe acute respiratory syndrome and other causes of community-acquired pneumonia? Clin Infect Dis. 2005:40(8):1079-86.

22. Collins GS, Ogundimu EO, Altman DG. Sample size considerations for the external validation of a multivariable prognostic model: a resampling study. Stat Med. 2016;35(2):214-26.

23. Vergouwe Y, Steyerberg EW, Eijkemans MJ, Habbema JD. Substantial effective sample sizes were required for external validation studies of predictive logistic regression models. J Clin Epidemiol. 2005;58(5):475-83.

24. Collins GS, de Groot JA, Dutton S, Omar O, Shanyinde M, Tajar A, et al. External validation of multivariable prediction models: a systematic review of methodological conduct and reporting. BMC Med Res Methodol. 2014;14:40.

25. Min YG, Ahn JH, Chan YC, Ng SH, Tse ML, Lau FL, et al. Prediction of prognosis in acute paraquat poisoning using severity scoring system in emergency department. Clin Toxicol. 2011:49(9):840-5.

26. Shafaf N, Malek H. Applications of machine learning approaches in emergency medicine; a review article. Arch Acad Emerg Med. 2019;7(1):34.

\section{Publisher's Note}

Springer Nature remains neutral with regard to jurisdictional claims in published maps and institutional affiliations.

Ready to submit your research? Choose BMC and benefit from

- fast, convenient online submission

- thorough peer review by experienced researchers in your field

- rapid publication on acceptance

- support for research data, including large and complex data types

- gold Open Access which fosters wider collaboration and increased citations

- maximum visibility for your research: over 100M website views per year

At BMC, research is always in progress.

Learn more biomedcentral.com/submissions 